\title{
Design and Synthesis of a Zeolitic Organic Framework
}

\author{
Yaozu Liu, ${ }^{\S, \dagger}$ Pohua Chen, ${ }^{\S, \dagger}$ Yujie Wang, ${ }^{* \dagger}$ Jinquan Suo, ${ }^{\dagger}$ Jiehua Ding, ${ }^{\dagger}$ Liangkui Zhu, ${ }^{\dagger}$ Valentin Valt- \\ chev, ${ }^{\perp, "}$ Y Yushan Yan, ${ }^{\#}$ Shilun Qiu, ${ }^{\dagger}$ Junliang Sun, ${ }^{*,+}$ and Qianrong Fang ${ }^{* \dagger}$ \\ ${ }^{\dagger}$ State Key Laboratory of Inorganic Synthesis and Preparative Chemistry, Jilin University, Changchun 130012, P. R. China \\ College of Chemistry and Molecular Engineering, Beijing National Laboratory for Molecular Sciences, Peking University, \\ Beijing 100871, China \\ ${ }^{\perp}$ Qingdao Institute of Bioenergy and Bioprocess Technology, Chinese Academy of Sciences, 189 Songling Road, Laoshan \\ District, Qingdao, Shandong 266101, P. R. China \\ "Normandie Univ, ENSICAEN, UNICAEN, CNRS, Laboratoire Catalyse et Spectrochimie, 6 Marechal Juin, 14050 Caen,
France
}

\#Department of Chemical and Biomolecular Engineering, Center for Catalytic Science and Technology, University of Delaware, Newark, DE 19716, USA

\section{Supporting Information Placeholder}

\begin{abstract}
The development of three-dimensional (3D) architectures in COFs has been considered important owing to their prospective advantages in high surface areas and plentiful active sites. Herein, we report the first example of a 3D COF with zeolitic network, namely the zeolitic organic framework (ZOF). By combining two kinds of tetrahedral building blocks with fixed or relatively free bond angles, ZOF-1 with the zeolitic crb net has been successfully synthesized. Its structure was determined by the single-crystal 3D electron diffraction technique. Remarkably, ZOF-1 shows high chemical stability, large pore size (up to $16 \AA$ ), and excellent specific surface area $\left(\sim 2785 \mathrm{~m}^{2} / \mathrm{g}\right)$, which is superior to its analogues with the same network, including traditional aluminosilicate zeolites and zeolitic imidazole frameworks. This study thus opens a new avenue to construct 3D COFs with zeolitic topologies and promotes the structural diversity and practical applications of COF materials.
\end{abstract}

Covalent organic frameworks $(\mathrm{COFs})^{1,2}$ are an emerging class of crystalline porous polymers that are assembled from organic building blocks linked by covalent bonds. Since the initiated work of Yaghi in 2005, ${ }^{1}$ these materials have attracted extensive attention in different fields, such as energy storage, gas separation, heterogeneous catalysis, optoelectronics, and many others. ${ }^{3-10}$ Recently, developing three-dimensional (3D) COF materials has been considered indispensable because of their promising advantages in interconnected pores and higher specific surface areas than two-dimensional (2D) counterparts. ${ }^{11-13}$ Up to now, the building units in 3D architectures are mostly on the basis of the tetrahedral (4-connected, $T_{d}$ ) geometry, such as the derivatives of tetraphenylmethane, tetraphenylsilane, and adamantine. ${ }^{14-16}$ Recently, a few successful examples with higher numbers of connections ( $>4$ points of extension) have been reported, e.g., a 3D cage-based COF with a twofold interpenetrated acs net ${ }^{17}$ and polycubane COFs with the bcu net based on cubic (8-connected) units. ${ }^{18}$ By applying triangular prism (6-connected, $D_{3 h}$ ) triptycene linkers as node centers, we also designed a series of 3D COFs with various networks, such as JUC-564 with stp net, ${ }^{19}$ JUC-568 and JUC-569 with ceq or acs net, ${ }^{20}$ as well as JUC-596 and JUC-597
Scheme 1. Energy scans analysis of tetrahedral building units as a function of bond angel ${ }^{\mathrm{a}}$

a)
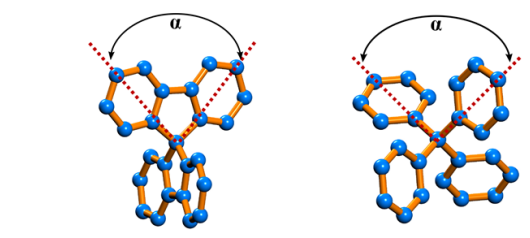

b)
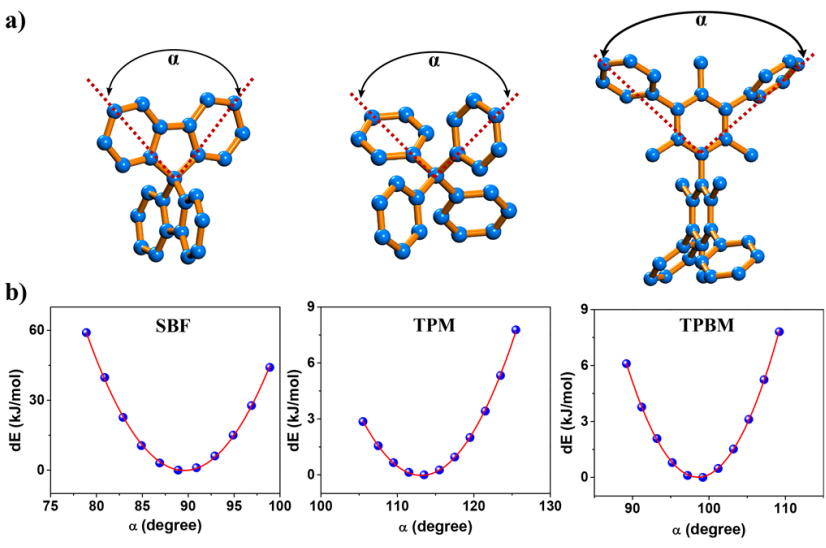

(a) Structures of SBF (left) with fixed bond angles as well as TPM (middle) and TPBM (right) with relatively free bond angles. (b) Potential energy scans of different tetrahedral building units based on variable bond angles.

with hea net. ${ }^{21}$ However, it is still a great challenge to obtain building units with a high extension due to the difficulties in the synthesis and purification. It should be noted that aluminosilicate zeolites as a widely-used crystalline porous material could be constructed to obtain more than 250 topologies by simple tetrahedral geometry $\left(\mathrm{SiO}_{4} \text { or } \mathrm{AlO}_{4}\right)^{22}$ In principle, more novel frameworks in 3D COFs, such as zeolite-like networks, could be also created by tetrahedral moieties as interlinked centers rather than just a limited number of topologies, e.g., dia, ctn, bor, and pts. ${ }^{23-30}$ However, this avenue has not yet been explored.

Herein, we report a 3D COF with the zeolitic net, namely zeolitic organic framework (ZOF). By employing two kinds of tetrahedral building units with fixed or relatively free bond angles, we successfully design and synthesize a crystalline porous ZOF with zeolitic crb net (namely zeolite BCT),${ }^{31}$ termed ZOF-1, which 
a)

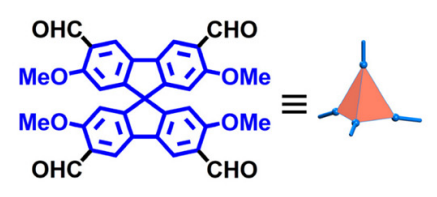

TMSFTA

b)

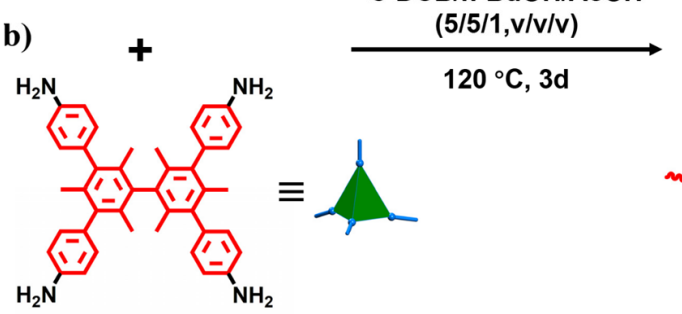

BMTA c)

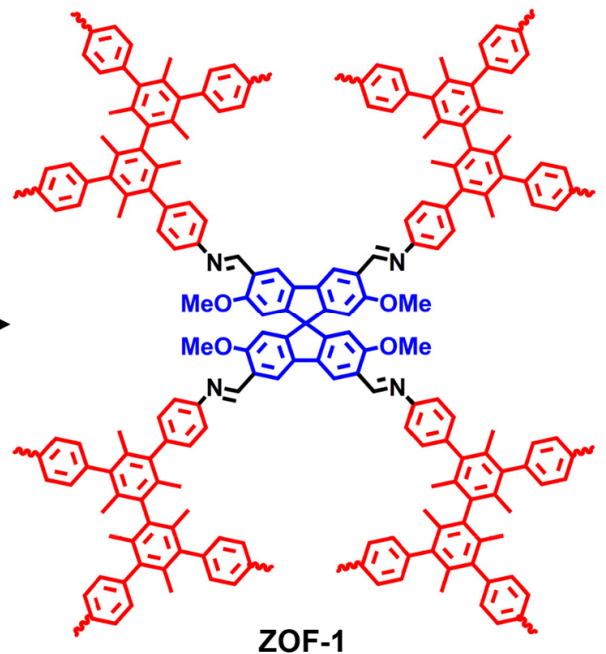

d)

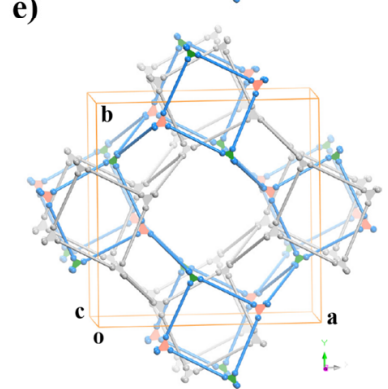

${ }^{a}$ Molecular structures of TMSFTA (a) as a tetrahedral building unit with fixed bond angles and BMTA (b) as a tetrahedral building unit with relatively free bond angles. A novel 3D COF with zeolitic crb net, ZOF-1 (c), constructed from the condensation reaction of TMSFTA and BMTA. Non-interpenetrated crb net (d) and twofold interpenetrated crb net (e).

has been determined its structure by the single-crystal 3D electron diffraction (ED) technique. Notably, ZOF-1 displays excellent chemical stability, large pore size $(\sim 16 \AA)$, and specific surface area $\left(\sim 2785 \mathrm{~m}^{2} / \mathrm{g}\right)$, which is much higher than its analogues with the same net, such as traditional aluminosilicate zeolites and zeolitic imidazole frameworks (ZIFs). To the best of our knowledge, this study represents the first case of 3D COFs with the zeolitic nets, promoting COF materials' structural diversity.

In order to construct a novel COF with the zeolitic net, our strategy is based on the reasonable regulation of tetrahedral building units by reticular chemistry. ${ }^{32}$ As shown in Scheme 1, we performed potential energy scans of three tetrahedral building units, 9,9'-spirobifluorene (SBF), tetraphenylmethane (TPM) and 3,3',5,5'-tetraphenyl-bimesitylene (TPBM), as the bond angles changed between $\pm 10^{\circ}$ by using Gaussian 09 software package. ${ }^{33}$ Obviously, the relatively free TPM and TPBM showed small energy changes $(\sim 8 \mathrm{~kJ} / \mathrm{mol})$, demonstrating that such building blocks are apt to form a traditional structure with dia net, an optimal conformation based on the lowest energy, by altering their bond angles. ${ }^{13}$ Different with flexible TPM and TPBM, SBF as a highly fixed linker exhibited major changes of the energy $(\sim 60$ $\mathrm{kJ} / \mathrm{mol}$ ), which indicates that it will probably tend to set up new architectures instead of the traditional optimal dia network due to the hard-to-change bond angles. Based on this strategy, we synthesized a derivative of SBF containing aldehyde groups, 2,2',7,7'-tetramethoxy-9, $9^{\prime}$-spirobifluorene-3,3',6,6'-

tetracarbaldehyde (TMSFTA, Scheme 2a). By the condensation of TMSFTA and a building unit containing amino groups, 3,3',5,5'tetra(p-aminophenyl)-bimesitylene (BMTA, Scheme 2b), we successfully developed the first 3D COF with the zeolitic net, ZOF1 (Scheme 2c).

Typically, the synthesis of ZOF-1 was carried out by suspending TMSFTA and BMTA in a mixed solution of n-butyl alcohol and 1,2-dichlorobenzene with the presence of $9 \mathrm{M}$ acetic acid aqueous solution, followed by heating at $120^{\circ} \mathrm{C}$ for 3 days. Complementary methods were employed for precise structural determination and characterization. Scanning electron microscopy (SEM) and image revealed that ZOF-1 exhibited approximate a)
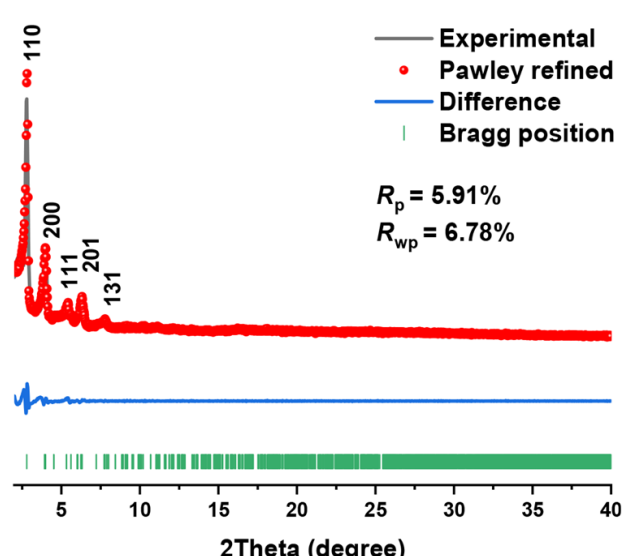

b)
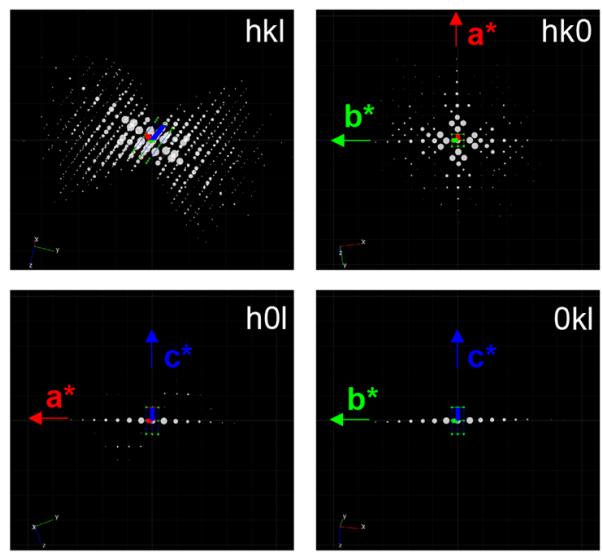

Figure 1. (a) Experimental and refined PXRD patterns of ZOF-1. (b) Merged 3D ED pattern with the same unit cell of ZOF-1. Upper left: overall 3D reciprocal lattice; upper right: h01 slice; lower left: $0 \mathrm{kl}$ slice; and lower right: hk0 slice. 
rectangular crystals (Figure S1). The Fourier transform infrared (FT-IR) spectra demonstrated the formation of ZOF-1 by a newly appeared $\mathrm{C}=\mathrm{N}$ stretching peak at $1615 \mathrm{~cm}^{-1}$ and the disappearance of N-H stretching band at $3310 \sim 3400 \mathrm{~cm}^{-1}$ and $\mathrm{C}=\mathrm{O}$ stretching band at $1696 \mathrm{~cm}^{-1}$, manifesting the completed conversion of Schiffbase polymerization (Figure S2). Solid-state ${ }^{13} \mathrm{C}$ cross-polarization magic-angle-spinning (CP/MAS) NMR spectroscopy of ZOF-1 further verified the presence of a new $\mathrm{C}=\mathrm{N}$ bond by the peak at 162 ppm (Figures S3). In addition, ZOF-1 showed high thermal stability (up to $350{ }^{\circ} \mathrm{C}$ ) according to the thermogravimetric analysis (TGA) under nitrogen gas (Figure S4), and excellent chemical stability for the stable existence in different organic solvents and aqueous solutions for $24 \mathrm{~h}$, such as strong acid $(\mathrm{HCl}$ with $\mathrm{pH}=1)$ and strong base $(\mathrm{NaOH}$ with $\mathrm{pH}=14$, Figure $\mathrm{S} 5)$.

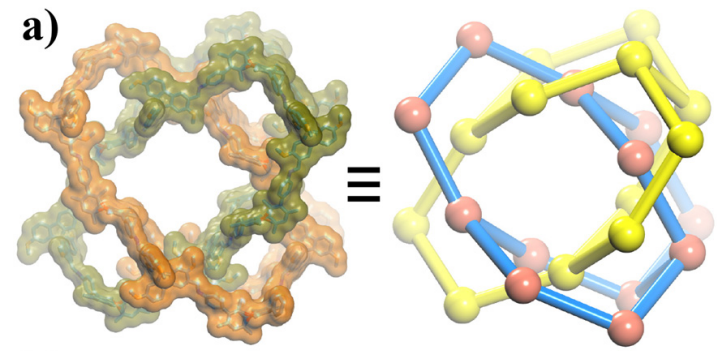

b)

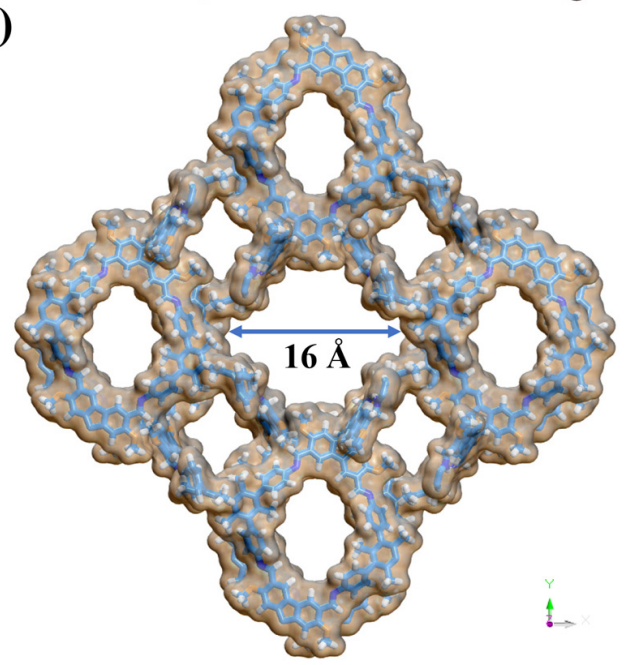

Figure 2. (a) Twofold interpenetrated cage in ZOF-1. (b) Extended porous framework of ZOF-1 viewed along the $\mathrm{c}$ axis. $\mathrm{C}$, sky blue; $\mathrm{H}$, gray; $\mathrm{N}$, blue; $\mathrm{O}$, yellow.

The unit cell and crystal structure of ZOF-1 were resolved by a 3D ED technique continuous rotation electron diffraction (cRED, Figures $1 \mathrm{~b}$ and S6). The cRED data were collected on a JEOL 2100-plus TEM equipped with MerlinEM direct electron detector under $200 \mathrm{kV}$ acceleration voltage at $100 \mathrm{~K}$. The data were visualized with program $\mathrm{RED}^{34}$ and processed using $\mathrm{XDS}^{35}$ with the aid of Instamatic ${ }^{36}$ for batch processing. These data were recorded with the tilting angle from $-51.12^{\circ}$ to $63.86^{\circ}$. Each frame was collected with an exposure time of $1 \mathrm{~s}$, resulting in a $0.75^{\circ}$ wedge per frame. The resolution cutoff was set to $2.0 \AA$ according to the criteria of $\mathrm{I} / \sigma>1$. The diffraction can be indexed with the cell parameter of $a$ $=30.37 \AA, b=30.00 \AA, c=18.71 \AA, \alpha=89.79^{\circ}, \beta=89.78^{\circ}$, and $\gamma$ $=90.09^{\circ}$. Pointless ${ }^{37}$ analysis indicated that the diffraction belongs to $C m m m$ Laue group and not to a tetragonal lattice. Thus, the unit cell was converted to an orthorhombic $C$-lattice with the cell parameters of $a=42.62 \AA, b=42.76 \AA, c=18.73 \AA$. Due to the low resolution $(2.0 \AA)$, we turned to the molecular replacement method (Phaser).$^{38}$ The initio positions of two monomers were found using this method, and they were then adjusted manually to form a continuous network. Finally, the model was optimized by Forcite module in the Materials Studio with COMPASS II force field (Table S1). ${ }^{39}$ In light of these results, ZOF-1 was defined as a 3D framework with twofold interpenetrated crb net and interconnected channels (up to $16 \AA$, Scheme 2d, 2e, and Figures 2, S10, S11).
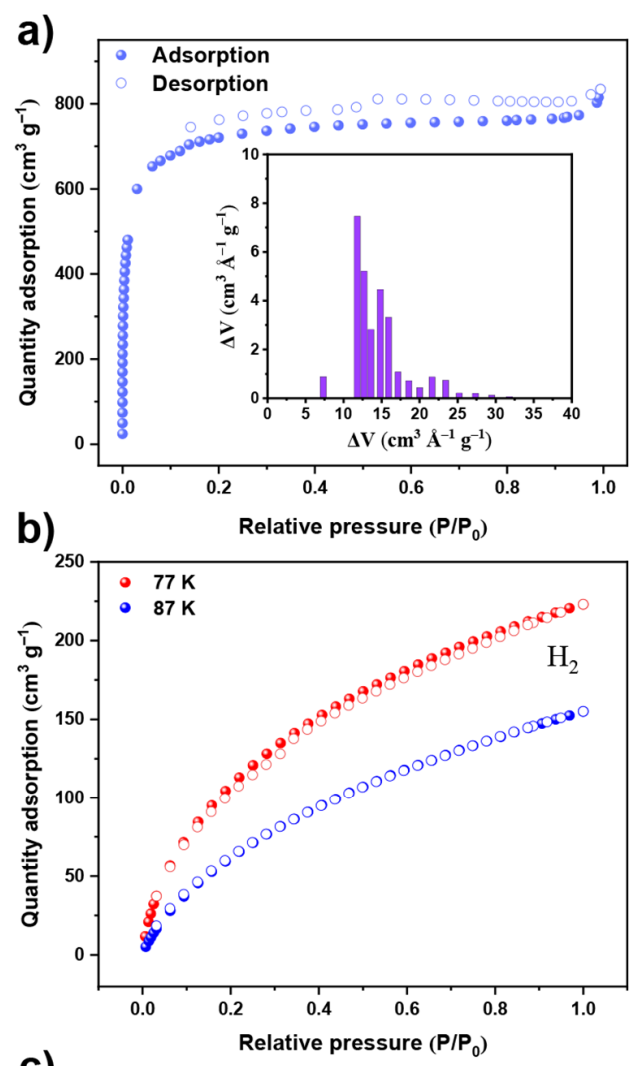

c)

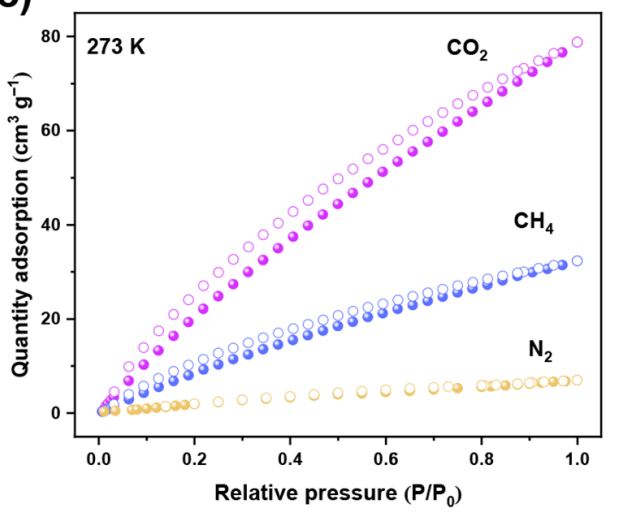

Figure 3. (a) $\mathrm{N}_{2}$ adsorption-desorption isotherm of ZOF-1 at 77 K. (b) $\mathrm{H}_{2}$ adsorption of ZOF-1 at $77 \mathrm{~K}$ and $87 \mathrm{~K}$. (c) Uptakes of $\mathrm{CO}_{2}, \mathrm{CH}_{4}$ and $\mathrm{N}_{2}$ of $\mathrm{ZOF}-1$ at $273 \mathrm{~K}$. Inset: pore-size distribution of ZOF-1.

The structure of ZOF-1 was also studied via powder X-ray diffraction (PXRD) combined with the structural simulation. The experimental PXRD pattern of ZOF-1 was in good agreement with the calculated one from the cRED model (Figure S7). Full profile pattern matching (Pawley) refinement was carried out. As shown in Figure 1a, peaks at $2.92^{\circ}, 4.13^{\circ}, 5.55^{\circ}, 6.29^{\circ}$, and $7.54^{\circ}$ could be attributed to the (110), (200), (111), (201), and (131) Bragg peaks. The refinement results yielded similar unit cell parameters with 
good agreement factors $(R \mathrm{p}=5.91 \%$ and $\omega R \mathrm{p}=6.78 \%)$. An alternative structure, a non-interpenetrated crb net, was also set up; however, its simulated PXRD did not match the experimental one (Figure S8).

The permanent porosity and specific surface area of ZOF-1 were obtained by $\mathrm{N}_{2}$ adsorption analysis at $77 \mathrm{~K}$. As shown in Figure 3a, a sharp increase was observed at low pressure (below 0.1 $\mathrm{P} / \mathrm{P}_{0}$ ), which reveals a microporous nature. The slight desorption hysteresis and inclination above $0.9 \mathrm{P} / \mathrm{P}_{0}$ can be attributed to textural mesopores from the agglomeration of crystals. ${ }^{40}$ According to its $\mathrm{N}_{2}$ adsorption isotherm, the Brunauer-Emmett-Teller (BET) specific surface area of ZOF-1 was as high as $2785 \mathrm{~m}^{2} / \mathrm{g}$ (Figure S9). Furthermore, the pore-size distribution was calculated by nonlocal density functional theory (NLDFT), which is in good agreement with those of the crystal structure (Figure 3a, inset). Remarkably, ZOF-1 displayed an impressive BET surface area $\left(2785 \mathrm{~m}^{2} / \mathrm{g}\right)$ and pore size (up to $16 \AA$ ) compared to zeolite-like materials with the same crb net, including traditional aluminosilicate zeolites and

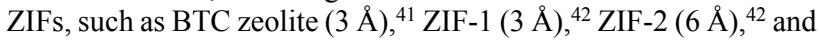
ZIF-64 (6 $\AA),{ }^{43}$ which demonstrates that such pure organic frameworks have fascinating potential due to their high surface areas and large pores (Table S2).

We further investigated the $\mathrm{H}_{2}$ adsorption performance of ZOF1. As shown in Figures 3 b, ZOF-1 showed a high capacity in $\mathrm{H}_{2}$ uptake up to $223 \mathrm{~cm}^{3} / \mathrm{g}(1.99 \mathrm{wt} \%)$ at $77 \mathrm{~K}$ and $154 \mathrm{~cm}^{3} / \mathrm{g}(1.38$ $\mathrm{wt} \%)$ at $87 \mathrm{~K}$ at $1 \mathrm{bar}$, which is comparable with best performing porous materials, such as CTC-COF $\left(125 \mathrm{~cm}^{3} / \mathrm{g}\right.$ or $\left.1.12 \mathrm{wt} \%\right),{ }^{44}$ MOF-177 (139 $\mathrm{cm}^{3} / \mathrm{g}$ or $\left.1.25 \mathrm{wt} \%\right),{ }^{45} \mathrm{PAF}-1\left(179 \mathrm{~cm}^{3} / \mathrm{g}\right.$ or 1.60 $\mathrm{wt} \%) .{ }^{46}$ Furthermore, the isosteric heat of adsorption $\left(\mathrm{Q}_{\mathrm{st}}\right)$ of ZOF1 for $\mathrm{H}_{2}$ was calculated to be $6.37 \mathrm{~kJ} / \mathrm{mol}$ (Figure S12). In addition, we studied the potential application of ZOF-1 for $\mathrm{CO}_{2}$ adsorption and separation. The adsorption isotherms of $\mathrm{CO}_{2}, \mathrm{~N}_{2}$, and $\mathrm{CH}_{4}$ were measured at $273 \mathrm{~K}$ (Figure 3c). Notably, the sorption amount of ZOF-1 for $\mathrm{CO}_{2}$ was as high as $78.78 \mathrm{~cm}^{3} / \mathrm{g}$, which is much higher than the other two gases, $\mathrm{CH}_{4}\left(32.34 \mathrm{~cm}^{3} / \mathrm{g}\right)$ and $\mathrm{N}_{2}\left(7.01 \mathrm{~cm}^{3} / \mathrm{g}\right)$. The ideal adsorption selectivity of ZOF-1 was calculated from the ratio of the initial slopes based on the Henry region of the isotherms (Figure S13), and good selectivity of $\mathrm{CO}_{2} / \mathrm{N}_{2}(6.7)$ or $\mathrm{CO}_{2} / \mathrm{CH}_{4}$ (19.1) was observed (Table S3).

In summary, we successfully designed and synthesized a crystalline porous ZOF with the zeolitic crb net by using two kinds of tetrahedral building blocks with fixed or relatively free bond angles, TMSFTA and BMTA. The crystal structure of ZOF-1 was well determined by a cRED technique as well as PXRD patterns combined with the structural simulation. Furthermore, ZOF-1 showed high chemical stability, large pore size $(\sim 16 \AA)$, and exceptional specific surface area $\left(\sim 2785 \mathrm{~m}^{2} / \mathrm{g}\right)$, which exceeds its analogues with the same framework involving traditional aluminosilicate zeolites and ZIFs. Therefore, this work expands the structural diversity of COF materials and their potential applications for adsorption and separation of large molecules.

\section{Supporting Information}

Methods and synthetic procedures, SEM, TEM, FTIR, solid state ${ }^{13} \mathrm{C}$ NMR, TGA, BET plot, and unit cell parameters. This material is available free of charge via the internet at http://pubs.acs.org.

\section{AUTHOR INFORMATION}

\section{Corresponding Author}

*wyujie@jlu.edu.cn, junliang.sun@pku.edu.cn,or qrfang@jlu.edu.cn

\section{Author Contributions}

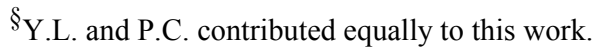

Notes

The authors declare no competing financial interests.

\section{ACKNOWLEDGMENT}

This work was supported by National Natural Science Foundation of China (22025504, 21621001, 21390394, and 22105082), "111" project (BP0719036 and B17020), China Postdoctoral Science Foundation (2020TQ0118 and 2020M681034), and the program for JLU Science and Technology Innovative Research Team. V.V., Q.F. and S.Q. acknowledge the collaboration in the framework of ChinaFrench joint laboratory "Zeolites".

\section{REFERENCES}

(1) Côté, A. P.; Benin, A. I.; Ockwig, N. W.; O'Keeffe, M.; Matzger, A. J.; Yaghi, O. M. Porous, Crystalline, Covalent Organic Frameworks. Science 2005, 310, 1166.

(2) El-Kaderi, H. M.; Hunt, J. R.; Mendoza-Cortes, J. L.; Côté, A. P.; Taylor, R. E.; O'Keeffe, M.; Yaghi, O. M. Designed Synthesis of 3D Covalent Organic Frameworks. Science 2007, 316, 268.3718

(3) Colson, J. W.; Woll, A. R.; Mukherjee, A.; Levendorf, M. P.; Spitler, E. L.; Shields, V. B.; Spencer, M. G.; Park, J.; Dichtel, W. R. Oriented 2D Covalent Organic Framework Thin Films on Single-Layer Graphene. Science 2011, 332, 228.

(4) Ding, S. Y.; Wang, W. Covalent Organic Frameworks (COFs): from Design to Applications. Chem. Soc. Rev. 2013, 42, 548.

(5) Lohse, M. S.; Bein, T. Covalent Organic Frameworks: Structures, Synthesis, and Applications. Adv. Funct. Mater. 2018, $28,1705553$.

(6) Rodríguez-San-Miguel, D.; Zamora, F. Processing of Covalent Organic Frameworks: An Ingredient for A Material to Succeed. Chem. Soc. Rev. 2019, 48, 4375.

(7) Kandambeth, S.; Dey, K.; Banerjee, R. Covalent Organic Frameworks: Chemistry beyond the Structure. J. Am. Chem. Soc. 2019, 141, 1807.

(8) Geng, K.; He, T.; Liu, R.; Dalapati, S.; Tan, K. T.; Li, Z.; Tao, S.; Gong, Y.; Jiang, Q.; Jiang, D. Covalent Organic Frameworks: Design, Synthesis, and Functions. Chem. Rev. 2020, $120,8814$.

(9) Alahakoon, S. B.; Diwakara, S. D.; Thompson, C. M.; Smaldone, R. A. Supramolecular Design in 2D Covalent Organic Frameworks. Chem. Soc. Rev. 2020, 49, 1344.

(10) Liu, R.; Tan, K. T.; Gong, Y.; Chen, Y.; Li, Z.; Xie, S.; He, T.; Lu, Z.; Yang, H.; Jiang, D. Covalent Organic Frameworks: An Ideal Platform for Designing Ordered Materials and Advanced Applications. Chem. Soc. Rev. 2021, 50, 120.

(11) Ma, X.; Scott, T. F. Approaches and Challenges in the Synthesis of Three-Dimensional Covalent-Organic Frameworks. Commun. Chem. 2018, 1, 98.

(12) Gui, B.; Lin, G. Q.; Ding, H. M.; Gao, C.; Mal, A.; Wang, C. Three-Dimensional Covalent Organic Frameworks: From Net Design to Applications. Acc. Chem. Res. 2020, 53, 2225.

(13) Guan, X. Y.; Chen, F. Q.; Fang, Q. R.; Qiu, S. L. Design and Applications of Three-Dimensional Covalent Organic Frameworks. Chem. Soc. Rev. 2020, 49, 1357.

(14) Ma, T. Q.; Kapustin, E. A.; Yin, S. X.; Liang, L.; Zhou, Z. Y.; Niu, J.; Li, L. H.; Wang, Y. Y.; Su, J.; Li, J.; Wang, X. G.; Wang, W. D.; Wang, W.; Sun, J. L.; Yaghi, O. M. Single-Crystal X-Ray Diffraction Structures of Covalent Organic Frameworks. Science 2018, 361, 48.

(15) Li, H.; Chang, J.; Li, S.; Guan, X.; Li, D.; Li, C.; Tang, L.; Xue, M.; Yan, Y.; Valtchev, V.; Qiu, S.; Fang, Q. ThreeDimensional Tetrathiafulvalene-Based Covalent Organic 
Frameworks for Tunable Electrical Conductivity. J. Am. Chem. Soc. 2019, 141, 13324.

(16) Gao, C.; Li, J.; Yin, S.; Sun, J.; Wang, C. Twist Building Blocks from Planar to Tetrahedral for the Synthesis of Covalent Organic Frameworks. J. Am. Chem. Soc. 2020, 142, 3718.

(17) Zhu, Q.; Wang, X.; Clowes, R.; Cui, P.; Chen, L. J.; Little, M. A.; Cooper, A. I. 3D Cage COFs: A Dynamic Three-Dimensional Covalent Organic Framework with High-Connectivity Organic Cage Nodes. J. Am. Chem. Soc. 2020, 142, 16842.

(18) Gropp, C.; Ma, T. Q.; Hanikel, N.; Yaghi, O. M. Design of Higher Valency in Covalent Organic Frameworks. Science 2020, $370,6406$.

(19) Li, H.; Ding, J. H.; Guan, X. Y.; Chen, F. Q.; Li, C. Y.; Zhu, L. K.; Xue, M.; Yuan, D. Q.; Valtchev, V.; Yan, Y. S.; Qiu, S. L.; Fang, Q. R. Three-Dimensional Large-Pore Covalent Organic Framework with stp Net. J. Am. Chem. Soc. 2020, 142, 13334.

(20) Li, H.; Chen, F. Q.; Guan, X. Y.; Li, J. L.; Li, C. Y.; Tang, B.; Valtchev, V.; Yan, Y. S.; Qiu, S. L.; Fang, Q. R. ThreeDimensional Triptycene-Based Covalent Organic Frameworks with ceq or acs Net. J. Am. Chem. Soc. 2021, 143, 2654.

(21) Yu, C. Y.; Li, H.; Wang, Y. J.; Suo, J. Q.; Guan, X. Y.; Wang, R.; Valtchev, V.; Yan, Y. S.; Qiu, S. L.; Fang, Q. R. ThreeDimensional Triptycene-Functionalized Covalent Organic Frameworks with hea net for Hydrogen Adsorption. Angew. Chem. Int. Ed. 2022, 61, DOI:10.1002/anie.202117101.

(22) http://www.iza-structure.org/databases/.

(23) Uribe-Romo, F. J.; Hunt, J. R.; Furukawa, H.; Klöck, C.; O'Keeffe, M.; Yaghi, O. M. A Crystalline Imine-Linked 3-D Porous Covalent Organic Framework. J. Am. Chem. Soc. 2009, 131, 4570.

(24) Lan, Y.; Han, X.; Tong, M.; Huang, H.; Yang, Q.; Liu, D.; Zhao, X.; Zhong, C. Materials Genomics Methods for HighThroughput Construction of COFs and Targeted Synthesis. Nat. Commun. 2018, 9, 5274.

(25) Zhang, Y.; Duan, J.; Ma, D.; Li, P.; Li, S.; Li, H.; Zhou, J.; Ma, X.; Feng, X.; Wang, B. Three-Dimensional Anionic Cyclodextrin-Based Covalent Organic Frameworks. Angew. Chem. Int. Ed. 2017, 56, 16313.

(26) Yahiaoui, O.; Fitch, A. N.; Hoffmann, F.; Froba, M.; Thomas, A.; Roeser, J. 3D Anionic Silicate Covalent Organic Framework with srs Net. J. Am. Chem. Soc. 2018, 140, 5330.

(27) Lin, G.; Ding, H.; Yuan, D.; Wang, B.; Wang, C. A PyreneBased Fluorescent Three-Dimensional Covalent Organic Framework. J. Am. Chem. Soc. 2016, 138, 3302.

(28) Nguyen, H. L.; Gropp, C.; Ma, Y.; Zhu, C.; Yaghi, O. M. 3D Covalent Organic Frameworks Selectively Crystallized through Conformational Design. J. Am. Chem. Soc. 2020, 142, 20335.

(29) Kang, X.; Han, X.; Yuan, C.; Cheng, C.; Liu, Y.; Cui, Y. Reticular Synthesis of tbo Net Covalent Organic Frameworks. $J$. Am. Chem. Soc. 2020, 142, 16346.

(30) Martínez-Abadía, M.; Strutyński, K.; Lerma-Berlanga, B.; Stoppiello, C. T.; Khlobystov, A. N.; Martí-Gastaldo, C.; Saeki, A.; Melle-Franco, M.; Mateo-Alonso, A. $\pi$-Interpenetrated 3D Covalent Organic Frameworks from Distorted Polycyclic Aromatic Hydrocarbons. Angew. Chem. Int. Ed. 2021, 60, 9941.

(31) http://rcsr.net/nets.

(32) Yaghi, O. M. Reticular Chemistry-Construction, Properties, and Precision Reactions of Frameworks. J. Am. Chem. Soc. 2016, 138, 15507.

(33) Frisch, M. J.; Trucks, G. W.; Schlegel, H. B.; Scuseria, G. E.; Robb, M. A.; Cheeseman, J. R.; Scalmani, G.; Barone, V.; Mennucci, B.; Petersson, G. A.; Nakatsuji, H.; Caricato, M.; Li, X.;

Hratchian, H. P.; Izmaylov, A. F.; Bloino, J.; Zheng, G. Sonnenberg, J. L.; Hada, M.; Ehara, M.; Toyota, K.; Fukuda, R.; Hasegawa, J.; Ishida, M.; Nakajima, T.; Honda, Y.; Kitao, O.; Nakai, H.; Vreven, T.; Montgomery Jr, J. A.; Peralta, J. E.; Ogliaro, F.; Bearpark, M.; Heyd, J. J.; Brothers, E.; Kudin, K. N.; Staroverov, V. N.; Kobayashi, R.; Normand, J.; Raghavachari, K.; Rendell, A.; Burant, J. C.; Iyengar, S. S.; Tomasi, J.; Cossi, M.; Rega, N.; Millam, J. M.; Klene, M.; Knox, J. E.; Cross, J. B.; Bakken, V.; Adamo, C.; Jaramillo, J.; Gomperts, R.; Stratmann, R. E.; Yazyev, O.; Austin, A. J.; Cammi, R.; Pomelli, C.; Ochterski, J. W.; Martin, R. L.; Morokuma, K.; Zakrzewski, V. G.; Voth, G. A.; Salvador, P.; Dannenberg, J. J.; Dapprich, S.; Daniels, A. D.; Farkas, Ö.; Foresman, J. B.; Ortiz, J. V.; Cioslowski J.; Fox, D. J. Gaussian 09, Gaussian, Inc., Wallingford, CT, 2009.

(34) Wan, W.; Sun, J.; Su, J.; Hovmoller, S.; Zou, X. Three-Dimensional Rotation Electron Diffraction: Software RED for Automated Data Collection and Data Processing. J. Appl. Crystallogr. 2013, 46, 1863.

(35) Kabsch, W. XDS. Acta Crystallogr. D Biol. Crystallogr. 2010, 66, 125.

(36) Cichocka, M. O.; Angstrom, J.; Wang, B.; Zou, X.; Smeets, S., High-Throughput Continuous Rotation Electron Diffraction Data Acquisition via Software Automation. J. Appl. Crystallogr. 2018, 51, 1652.

(37) Evans, P. An Introduction to Data Reduction: Space-Group Determination, Scaling and Intensity Statistics. Acta Crystallogr. D 2011, 67, 282.

(38) McCoy, A. J.; Grosse-Kunstleve, R. W.; Adams, P. D.; Winn, M. D.; Storoni, L. C.; Read, R. J. Phaser Crystallographic Software. J. Appl. Crystallogr. 2007, 40, 658.

(39) Materials Studio ver. 7.0; Accelrys Inc.: San Diego, CA.

(40) Yan, S. C.; Guan, X. Y.; Li, H.; Li, D. H.; Xue, M.; Yan, Y. S.; Valtchev, V.; Qiu, S. L.; Fang, Q. R. Three-Dimensional Salphen-based Covalent Organic Frameworks as Catalytic Antioxidants. J. Am. Chem. Soc. 2019, 141, 2920.

(41) Dollase, W. A.; Ross, C. R. Crystal Structures of the BodyCentered Tetragonal Tectosilicates: $\mathrm{K}_{1.14} \mathrm{Mg}_{0.57} \mathrm{Si}_{1.43} \mathrm{O}_{4}$, $\mathrm{K}_{1.10} \mathrm{Zn}_{0.55} \mathrm{Si}_{1.45} \mathrm{O}_{4}$, and $\mathrm{K}_{1.11} \mathrm{Fe}_{1.11} \mathrm{Si}_{0.89} \mathrm{O}_{4}$. Am. Mineral. 1993, 78, 627.

(42) Park, K. S.; Ni, Z.; Côté, A. P.; Choi, J. Y.; Huang, R. D.; Uribe-Romo, F. J.; Chae, H. K.; O'Keeffe, M.; Yaghi, O. M. Exceptional Chemical and Thermal Stability of Zeolitic Imidazolate Frameworks. Proc. Natl. Acad. Sci. U.S.A. 2006, 103, 10186.

(43) Banerjee, R.; Phan, A.; Wang, B.; Knobler, C.; Furukawa, H.; O'Keeffe, M.; Yaghi, O. M. High-Throughput Synthesis of Zeolitic Imidazolate Frameworks and Application to $\mathrm{CO}_{2}$ Capture. Science 2008, 319, 939.

(44) Yu, J. T.; Chen, Z.; Sun, J.; Huang, Z. T.; Zheng, Q. Y. Cyclotricatechylene based Porous Crystalline Material: Synthesis and Applications in Gas Storage. J. Mater. Chem. 2012, 22, 5369.

(45) Rowsell, J. L. C.; Millward, A. R.; Park, K. S.; Yaghi, O. M. Hydrogen Sorption in Functionalized Metal-Organic Frameworks. J. Am. Chem. Soc. 2004, 126, 5666.

(46) Ben, T.; Ren, H.; Ma, S.; Cao, D.; Lan, J.; Jing, X.; Wang, W.; Xu, J.; Deng, F.; Simmons, J. M.; Qiu, S.; Zhu, G. Targeted Synthesis of a Porous Aromatic Framework with High Stability and Exceptionally High Surface Area. Angew. Chem. Int. Ed. 2009, 48, 9457. 
TOC Graphic:
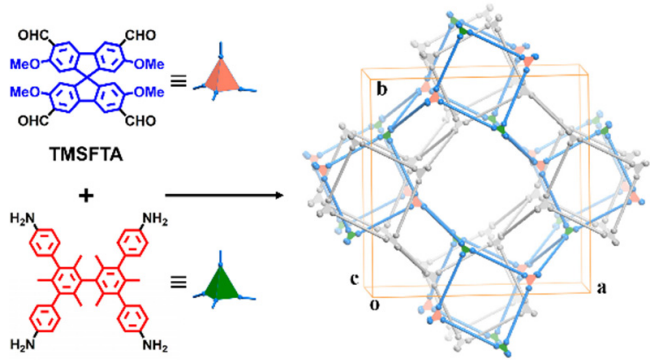

BMTA 